Journal of Mathematics and Statistics 7 (2): 107-111, 2011

ISSN 1549-3644

(C) 2010 Science Publications

\title{
Fuzzy Subalgebras and Fuzzy T-ieals in TM-Algebras
}

\author{
${ }^{1}$ Kandasamy Megalai and ${ }^{2}$ Angamuthu Tamilarasi \\ ${ }^{1}$ Department of Mathematics, Bannari Amman Institute of Technology, \\ Sathyamangalam, Tamilnadu, India \\ ${ }^{2}$ Department of Computer Science, \\ Kongu Engineering College, Perundurai, Tamilnadu, India
}

\begin{abstract}
In this study, we introduce the concepts of fuzzy subalgebras and fuzzy ideals in TM-algebras and investigate some of its properties. Problem statement: Let X be a TM-algebra, S be a subalgebra of X and I be a T-ideal of X. Let $\mu$ and $v$ be fuzzy sets in a TM-algebra X. Approach: Define the upper level subset $\mu_{\mathrm{t}}$ of $\mu$ and the cartesian product of $\mu$ and $\mathrm{v}$ from $\mathrm{X} \times \mathrm{X}$ to [0,1] by minimum of $\mu(\mathrm{x})$ and $\mathrm{v}(\mathrm{y})$ for all elements $(\mathrm{x}, \mathrm{y})$ in $\mathrm{X} \times \mathrm{X}$. Result: We proved any subalgebra of a TM-algebra $\mathrm{X}$ can be realized as a level subalgebra of some fuzzy subalgebra of $X$ and $\mu_{t}$ is a T-ideal of $X$. Also we proved, the cartesian product of $\mu$ and $v$ is a fuzzy $T$-ideal of $X \times X$. Conclusion: In this article, we have fuzzified the subalgebra and ideal of TM-algebras into fuzzy subalgrbra and fuzzy ideal of TM-algebras. It has been observed that the TM-algebra satisfy the various conditions stated in the BCC/ BCK algebras. These concepts can further be generalized.
\end{abstract}

Key words: TM-algebra, fuzzy subalgebra, fuzzy ideals, homomorphism, cartesian product, level subset, conditions stated

\section{INTRODUCTION}

Isaki and Tanaka introduced two classes of abstract algebras BCI-algebras and BCK-algebras. It is known that the class of BCK-algebras is a proper subclass of the class of BCI- algebra. Hu and Li introduced a wide class of abstract algebra namely $\mathrm{BCH}$ - algebras. Zadeh (1965), introduced the notion of fuzzy sets in 1965. This concept has been applied to many mathematical branches. $\mathrm{Xi}$ applied this concept to BCK-algebra. Dudek and Jun (2001) fuzzified the ideals in BCCalgebras. Jun (2009) contributed a lot to develop the theory of fuzzy sets.

We (Megalai and Tamilarasi, 2010) introduced a new notion called TM-algebra, which is a generalization of $\mathrm{Q} / \mathrm{BCK} / \mathrm{BCI} / \mathrm{BCH}$-algebras and investigated some properties. In this study, we introduce the concepts of fuzzy subalgebras and fuzzy T-ideals in TM-algebra and investigate some of their properties.

\section{MATERIALS AND METHODS}

Certain fundamental definitions that will be used in the sequel are described.

Preliminaries:
Definition 1: A BCK-algebra is an algebra $\left(X,{ }^{*}, 0\right)$ of type $(2,0)$ satisfying the following conditions:

- $\left(\mathrm{x}^{*} \mathrm{y}\right)^{*}\left(\mathrm{x}^{*} \mathrm{z}\right) \leq \mathrm{z}^{*} \mathrm{y}$

- $\mathrm{x}^{*}\left(\mathrm{x}^{*} \mathrm{y}\right) \leq \mathrm{y}$

- $\mathrm{x} \leq \mathrm{x}$,

- $\mathrm{x} \leq \mathrm{y}$ and $\mathrm{y} \leq \mathrm{x}$ imply $\mathrm{x}=\mathrm{y}$,

- $0 \leq \mathrm{x}$ implies $\mathrm{x}=0$, where $\mathrm{x} \leq \mathrm{y}$ is defined by

- $\mathrm{x}^{*} \mathrm{y}=0$ for all $\mathrm{x}, \mathrm{y}, \mathrm{z} \in \mathrm{X}$.

Definition 2: Let I be a non- empty subset of a BCKalgebra X. Then $\mathrm{I}$ is called a BCK-ideal of X if:

- $0 \in \mathrm{I}$,

- $\mathrm{x}^{*} \mathrm{y} \in \mathrm{I}$ and $\mathrm{y} \in \mathrm{I}$ imply $\mathrm{x} \in \mathrm{I}$, for all $\mathrm{x}, \mathrm{y} \in \mathrm{x}$

Definition 3: A TM-algebra $\left(X,{ }^{*}, 0\right)$ is a non-empty set $\mathrm{X}$ with a constant " 0 " and a binary operation "** " satisfying the following axioms:

- $\quad \mathrm{x}^{*} 0=\mathrm{x}$

- $\left(x^{*} y\right)^{*}\left(x^{*} z\right)=z^{*} y$, for any $x, y, z \in X$

In $\mathrm{X}$ we can define a binary relation $\leq$ by $\mathrm{x} \leq \mathrm{y}$ if and only if $x^{*} \mathrm{y}=0$.
Correspond Author: Kandasamy Megalai, Department Sathyamangalam, Tamilnadu, India of Mathematics,Bannari Amman Institute of Technology, 
Definition 4: Let $\mathrm{S}$ be a non-empty subset of a TMalgebra $\mathrm{X}$. Then $\mathrm{S}$ is called a subalgebra of $\mathrm{X}$ if $\mathrm{x} * \mathrm{y} \in \mathrm{S}$, for all $\mathrm{x}, \mathrm{y} \in \mathrm{X}$.

Definition 5: Let $\left(X,{ }^{*}, 0\right)$ be a TM-algebra. A nonempty subset I of $X$ is called an ideal of $X$ if it satisfies

- $0 \in 1$

- $\quad x * y \in I$ and $y \in I$ imply $x \in I$, for all $x, y \in X$.

Definition 6: An ideal A of a TM-algebra $X$ is said to be closed if $0 * \mathrm{x} \in \mathrm{A}$ for all $\mathrm{x} \in \mathrm{A}$.

Definition 7: Let $\left(X,{ }^{*}, 0\right)$ be a TM-algebra. A nonempty sub set $I$ of $X$ is called a $T$ - ideal of $X$ if it satisfies

- $0 \in \mathrm{I}$

- $\left(x^{*} y\right)^{*} z \in I$ and $y \in I$ imply $x * z \in I$, for all $\mathrm{x}, \mathrm{y}, \mathrm{z} \in \mathrm{X}$.

Fuzzy subalgebras:

Definition 8: Let $X$ be a non-empty set. A mapping $\mu: \mathrm{x} \rightarrow[0,1]$ is called a fuzzy set in $\mathrm{X}$. The complement of $\mu$, denoted by $\bar{\mu}(\mathrm{x})=1-\mu(\mathrm{x})$, for all $\mathrm{x} \in \mathrm{X}$.

Definition 9: A fuzzy set $\mu$ in a TM-algebra $X$ is called a fuzzy subalgebra of $X$ if

$\mu(x * y) \geq \min \{\mu(x), \mu(y)\}$, for all $x, y \in X$.

Definition 10: Let $\mu$ be a fuzzy set of a set $X$. For a fixed $t \in[0,1]$, the set $\mu_{t}=\{x \in X / \mu(x) \geq t\}$ is called an upper level of $\mu$.

Fuzzy T-ideals in TM-algebras:

Definition 11: A fuzzy subset $\mu$ in a TM-algebra $X$ is called a fuzzy ideal of $X$, if:

- (i) $\mu(0) \geq \mu(x)$

- (ii) $\mu(\mathrm{x}) \geq \min \{\mu(\mathrm{x} * \mathrm{y}), \mu(\mathrm{y})\}$ for all $\mathrm{x}, \mathrm{y}, \mathrm{z} \in \mathrm{X}$

Definition 12: A fuzzy subset $\mu$ in a TM-algebra $X$ is called a fuzzy $\mathrm{T}$-ideal of $\mathrm{X}$, if:

- $\mu(0) \geq \mu(x)$

- $\mu\left(x^{*} \mathrm{z}\right) \geq \min \left\{\mu\left(\left(\mathrm{x}^{*} \mathrm{y}\right)^{*} \mathrm{z}\right), \mu(\mathrm{y})\right\}$, for all $\mathrm{x}, \mathrm{y}, \mathrm{z}$ $\in \mathrm{X}$

\section{RESULTS}

Lemma 13: If $\mu$ is a fuzzy subalgebra of a TM-algebra $X$, then $\mu(0) \geq \mu(x)$ for any $x \in X$.

Proof: Since $\mathrm{x}^{*} \mathrm{x}=0$ for any $\mathrm{x} \in \mathrm{X}$, then:

$\mu(0)=\mu\left(x^{*} x\right) \geq \min \{\mu(x), \mu(x)\}=\mu(x)$.

This completes the proof.

Theorem 14: A fuzzy set $\mu$ of a TM-algebra $X$ is a fuzzy subalgebra if and only if for every $t \in[0,1], \mu_{t}$ is either empty or a subalgebra of X.

Proof: Assume that $\mu$ is a fuzzy subalgebra of $\mathrm{X}$ and $\mu_{\mathrm{t}}$ $\neq \varphi$. Then for any $\mathrm{x}, \mathrm{y} \in \mu_{\mathrm{t}}$, we have:

$\mu\left(x^{*} y\right) \geq \min \{\mu(x), \mu(y)\} \geq t$.

Therefore $\mathrm{x} * \mathrm{y} \in \mu_{\mathrm{t}}$.

Hence $\mu_{\mathrm{t}}$ is a subalgebra of $X$.

Conversely, $\mu_{\mathrm{t}}$ is a subalgebra of $\mathrm{X}$.

Let $\mathrm{x}, \mathrm{y} \in \mathrm{X}$. Take $\mathrm{t}=\min \{\mu(\mathrm{x}), \mu(\mathrm{y})\}$.

Then by assumption $\mu_{\mathrm{t}}$ is a subalgebra of $\mathrm{X}$ implies:

$\mathrm{x}^{*} \mathrm{y} \in \mu_{\mathrm{t}}$

Therefore $\mu\left(x^{*} y\right) \geq t=\min \{\mu(x), \mu(y)\}$.

Hence $\mu$ is a subalgebra of $X$.

Theorem 15: Any subalgebra of a TM-algebra $X$ can be realized as a level subalgebra of some fuzzy subalgebra of X.

Proof: Let $\mu$ be a subalgebra of a given TM-algebra X and let $\mu$ be a fuzzy set in $\mathrm{X}$ defined by:

$\mu(x)=\left\{\begin{array}{l}t, \text { if } x \in A \\ 0, \text { if } x \notin A\end{array}\right.$

where, $\mathrm{t} \in(0,1)$ is fixed. It is clear that $\mu_{\mathrm{t}}=\mathrm{A}$.

Now we will prove that such defined $\mu$ is a fuzzy subalgebra of X.

Let $\mathrm{x}, \mathrm{y} \in \mathrm{X}$. If $\mathrm{x}, \mathrm{y} \in \mathrm{A}$ then also $\mathrm{x} * \mathrm{y} \in \mathrm{A}$.

Hence $\mu(\mathrm{x})=\mu(\mathrm{y})=\mu\left(\mathrm{x}^{*} \mathrm{y}\right)=\mathrm{t}$ and

$\mu\left(x^{*} y\right) \geq \min \{\mu(\mathrm{x}), \mu(\mathrm{y})\}$. 
If $\mathrm{x}, \mathrm{y} \notin \mathrm{A}$ then $\mu(\mathrm{x})=\mu(\mathrm{y})=0$ and in the consequence $\mu\left(x^{*} y\right) \geq \min \{\mu(x), \mu(y)\}=0$.

If at most one of $\mathrm{x}$, $\mathrm{y}$ belongs to $\mathrm{A}$, then at least one of $\mu(\mathrm{x})$ and $\mu(\mathrm{y})$ is equal to 0 .

Therefore, $\min \{\mu(\mathrm{x}), \mu(\mathrm{y})\}=0$ so that:

$\mu\left(x^{*} y\right) \geq 0$, which completes the proof

Theorem 16: Two level subalgebras $\mu_{\mathrm{s}}, \mu_{\mathrm{t}}(\mathrm{s}<\mathrm{t})$ of a fuzzy subalgebra are equal if and only if there is no $\mathrm{x} \in \mathrm{X}$ such that $\mathrm{s} \leq \mu(\mathrm{x})<\mathrm{t}$.

Proof: Let $\mu_{\mathrm{s}}=\mu_{\mathrm{t}}$ for some $\mathrm{s}<\mathrm{t}$. If there exits $\mathrm{x} \in \mathrm{X}$ such that $s \leq \mu(\mathrm{x})<\mathrm{t}$, then $\mu_{\mathrm{t}}$ is a proper subset of $\mu_{\mathrm{s}}$, which is a contradiction.

Conversely, assume that there is no $\mathrm{x} \in \mathrm{X}$ such that $\mathrm{s} \leq \mu(\mathrm{x})<\mathrm{t}$. If $\mathrm{x} \in \mu_{\mathrm{s}}$, then $\mu(\mathrm{x}) \geq \mathrm{s}$ and $\mu(\mathrm{x}) \geq \mathrm{t}$, since $\mu(\mathrm{x})$ does not lie between $s$ and $t$. Thus $\mathrm{x} \in \mu_{\mathrm{t}}$, which gives $\mu_{\mathrm{s}} \subseteq \mu_{\mathrm{t}-}$ Also $\mu_{\mathrm{t}} \subseteq \mu_{\mathrm{s}}$. Therefore $\mu_{\mathrm{s}}=\mu_{\mathrm{t}}$

Theorem 17: Every fuzzy T-ideal $\mu$ of a TM-algebra $X$ is order reversing, that is if $\mathrm{x} \leq \mathrm{y}$ then:

$\mu(\mathrm{x}) \geq \mu(\mathrm{y})$ for all $\mathrm{x}, \mathrm{y} \in \mathrm{X}$.

Proof: Let $x . y \in X$ such that $x \leq y$.

Therefore $\mathrm{x}^{*} \mathrm{y}=0$.

Now, $\mu(\mathrm{x})=\mu\left(\mathrm{x}^{*} 0\right)$

$\geq \min \left\{\mu\left(\left(x^{*} y\right)^{*} 0\right), \mu(y)\right\}$

$=\min \{\mu(0 * 0), \mu(y)\}$

$=\min \{\mu(0), \mu(y)\}$

$=\mu(\mathrm{y})$.

Theorem 18: A fuzzy set $\mu$ in a TM-algebra $X$ is a fuzzy T-ideal if and only if it is a fuzzy ideal of $\mathrm{X}$.

Proof: Let $\mu$ be a fuzzy T-ideal of $X$

Then (i) $\mu(0) \geq \mu$ (x) and

(ii) $\mu\left(\mathrm{x}^{*} \mathrm{z}\right) \geq \min \left\{\mu\left(\left(\mathrm{x}^{*} \mathrm{y}\right) * \mathrm{z}\right), \mu(\mathrm{y})\right\}$ for all $\mathrm{x}, \mathrm{y}, \mathrm{z} \in \mathrm{X}$.

By putting $z=0$ in (ii) we have

$\mu(\mathrm{x}) \geq \min \{\mu(\mathrm{x} * \mathrm{y}), \mu(\mathrm{y})$.

Hence $\mu$ is a fuzzy ideal of $X$.

Conversely, $\mu$ is a fuzzy ideal of $\mathrm{X}$.

Then:

$\mu\left(x^{*} \mathrm{z}\right) \geq \min \left\{\mu\left(\left(\mathrm{x}^{*} \mathrm{z}\right)^{*} \mathrm{y}\right), \mu(\mathrm{y})\right\}$ $=\min \left\{\mu\left(\left(\mathrm{x}^{*} \mathrm{y}\right){ }^{*} \mathrm{z}\right), \mu(\mathrm{y})\right\}$, which proves the result.

Theorem 19: Let $\mu$ be a fuzzy set in a BCK-algebra X. Then $\mu$ is a fuzzy T-ideal if and only if $\mu$ is a fuzzy BCK-ideal.

Proof: Since every BCK-algebra is a TM-algebra, every fuzzy T-ideal is a fuzzy ideal of a TM-algebra and hence a fuzzy BCK-ideal.

Conversely, assume that $\mu$ be a BCK-ideal of X.

Then:

$\mu\left(\mathrm{x}^{*} \mathrm{z}\right) \geq \min \left\{\mu\left(\left(\mathrm{x}^{*} \mathrm{z}\right)^{*} \mathrm{y}\right), \mu(\mathrm{y})\right\}$

$=\min \left\{\mu\left(\left(x^{*} y\right) * z\right), \mu(y)\right\}$.

Hence $\mu$ is a fuzzy T-ideal of $\mathrm{X}$.

Theorem 20: Let $\mu$ be a fuzzy set in a TM-algebra $X$ and let $t \in \operatorname{Im}(\mu)$. Then $\mu$ is a fuzzy T-ideal of $X$ if and only if the level subset:

$\mu_{\mathrm{t}}=\{\mathrm{x} \in \mathrm{X} / \mu(\mathrm{x}) \geq \mathrm{t}\}$

is a T-ideal of X, which is called a level T-ideal of $\mu$.

Proof: Assume that $\mu$ is a fuzzy T-ideal of X.

Clearly $0 \in \mu_{\mathrm{t}}$

Let $\left(\mathrm{x}^{*} \mathrm{y}\right){ }^{*} \mathrm{z} \in \mu_{\mathrm{t}}$ and $\mathrm{y} \in \mu_{\mathrm{t}}$

Then $\mu((\mathrm{x} * \mathrm{y}) * \mathrm{z}) \geq \mathrm{t}$ and $\mu(\mathrm{y}) \geq \mathrm{t}$.

Now $\mu\left(x^{*} \mathrm{z}\right) \geq \min \left\{\mu\left(\left(x^{*} \mathrm{y}\right) * z\right), \mu(y)\right\}$

$\geq\{\mathrm{t}, \mathrm{t}\}=\mathrm{t}$

Hence $\mu_{t}$ is T-ideal of X.

Conversely, let $\mu_{t}$ is T-ideal of $X$ for any $t \in[0,1]$.

Suppose assume that there exist some $\mathrm{x}_{0} \in \mathrm{X}$ such that $\mu(0)<\mu\left(\mathrm{x}_{0}\right)$ :

Take $s=\frac{1}{2}\left[\mu(0)+\mu\left(x_{0}\right)\right]$

$\Rightarrow \mathrm{s}<\mu\left(\mathrm{x}_{0}\right)$ and $0 \leq \mu(0)<\mathrm{s}<1$

$\Rightarrow \mathrm{x}_{0} \in \mu_{\mathrm{s}}$ and $0 \notin \mu_{\mathrm{s}}$ a contradiction, since

$\mu_{\mathrm{s}}$ is a T-ideal of $\mathrm{X}$. 
Therefore, $\mu(0) \geq \mu(\mathrm{x})$ for all $\mathrm{x} \in \mathrm{X}$

If possible, assume that $\mathrm{x}_{0}, \mathrm{y}_{0}, \mathrm{z}_{0} \in \mathrm{X}$ such that $\mu\left(\mathrm{x}_{0} * \mathrm{z}_{0}\right) \geq \min \left\{\mu\left(\left(\mathrm{x}_{0}{ }^{*} \mathrm{y}_{0}\right){ }^{*} \mathrm{z}_{0}\right), \mu\left(\mathrm{y}_{0}\right)\right\}$ :

Take $\mathrm{s}=\frac{1}{2}\left[\mu\left(\mathrm{x}_{0} * \mathrm{z}_{0}\right)+\min \left\{\mu\left(\mathrm{x}_{0} * \mathrm{y}_{0}\right) * \mathrm{z}_{0}\right), \mu\left(\mathrm{y}_{0}\right)\right\}$

$\Rightarrow \mathrm{s}>\mu\left(\mathrm{x}_{0} * \mathrm{z}_{0}\right)$

and:

$\mathrm{s}<\min \left\{\mu\left(\left(\mathrm{x}_{0} * \mathrm{y}_{0}\right) * \mathrm{z}_{0}\right), \mu\left(\mathrm{y}_{0}\right)\right\}$

$\Rightarrow \mathrm{s}>\mu\left(\mathrm{x}_{0} * \mathrm{z}_{0}\right), \mathrm{s}<\mu\left(\left(\mathrm{x}_{0} * \mathrm{y}_{0}\right) * \mathrm{z}_{0}\right)$ and $\mathrm{s}<\mu\left(\mathrm{y}_{0}\right)$

$\Rightarrow \mathrm{x}_{0} * \mathrm{Z}_{0} \notin \mu_{\mathrm{s}}$, a contradiction, since $\mu_{\mathrm{S}}$ is a $\mathrm{T}$-ideal of $\mathrm{X}$.

Therefore, $\mu(\mathrm{x} * \mathrm{z}) \geq \min \{\mu((\mathrm{x} * \mathrm{y}) * \mathrm{z}), \mu(\mathrm{y})\}$ for any $\mathrm{x}, \mathrm{y}, \mathrm{z} \in \mathrm{X}$.

\section{Cartesian product of fuzzy T-ideals of TM-algebras:}

Definition 21: Let $\mu$ and $v$ be the fuzzy sets in a set $X$. The Cartesian product $\mu \times \mathrm{v}: \mathrm{X} \times \mathrm{X} \rightarrow[0,1]$ is defined by:

$(\mu \times v)(x, y)=\min \{\mu(x), v(y)\}$ for all $x, y \in X$

Theorem 22: If $\mu$ and $v$ are fuzzy T-ideals in a TMalgebra $\mathrm{X}$, then $\mu \times_{\mathrm{V}}$ is a fuzzy T-ideal in $\mathrm{X} \times \mathrm{X}$.

Proof: For any $(\mathrm{x}, \mathrm{y}) \in \mathrm{X} \times \mathrm{X}$, we have:

$(\mu \times \mathrm{v})(0,0)=\min \{\mu(0), \mathrm{v}(0)\}$

$\geq \min \{\mu(\mathrm{x}), \mathrm{v}(\mathrm{y})\}=(\mu \times \mathrm{v})(\mathrm{x}, \mathrm{y})$.

Let $\left(\mathrm{x}_{1}, \mathrm{x}_{2}\right),\left(\mathrm{y}_{1}, \mathrm{y}_{2}\right)$ and $\left(\mathrm{z}_{1}, \mathrm{z}_{2}\right) \in \mathrm{X} \times \mathrm{X}$.

$(\mu \times \mathrm{v})\left(\left(\mathrm{x}_{1}, \mathrm{x}_{2}\right) *\left(\mathrm{z}_{1}, \mathrm{z}_{2}\right)\right)=(\mu \times \mathrm{v})\left(\mathrm{x}_{1} * \mathrm{z}_{1}, \mathrm{x}_{2}{ }^{*} \mathrm{z}_{2}\right)$

$=\min \left\{\mu\left(\mathrm{x}_{1} * \mathrm{z}_{1}\right), \mathrm{v}\left(\mathrm{x}_{2} * \mathrm{z}_{2}\right)\right\}$

$\geq \min \left\{\min \left\{\mu\left(\left(\mathrm{x}_{1} * \mathrm{y}_{1}\right) * \mathrm{z}_{1}\right), \mu\left(\mathrm{y}_{1}\right)\right\}, \min \left\{\mathrm{v}\left(\left(\mathrm{x}_{2} * \mathrm{y}_{2}\right)\right.\right.\right.$

$\left.\left.\left.* \mathrm{z}_{2}\right), \mathrm{v}\left(\mathrm{y}_{2}\right)\right\}\right\}$

$=\min \left\{\min \left\{\mu\left(\left(\mathrm{x}_{1} * \mathrm{y}_{1}\right) * \mathrm{z}_{1}\right), \mathrm{v}\left(\left(\mathrm{x}_{2} * \mathrm{y}_{2}\right) * \mathrm{z}_{2}\right)\right\}\right.$,

$\left.\min \left\{\mu\left(\mathrm{y}_{1}\right), \mathrm{v}\left(\mathrm{y}_{2}\right)\right\}\right\}$

$=\min \left\{(\mu \times v)\left(\left(x_{1} * y_{1}\right) * z_{1},\left(x_{2} * y_{2}\right) * z_{2}\right)\right.$,

$\left.(\mu \times v)\left(\mathrm{y}_{1}, \mathrm{y}_{2}\right)\right\}$

$=\min \left\{(\mu \times \mathrm{v})\left(\left(\mathrm{x}_{1} * \mathrm{y}_{1}, \mathrm{x}_{2} * \mathrm{y}_{2}\right) *\left(\mathrm{z}_{1}, \mathrm{z}_{2}\right)\right)\right.$,

$\left.(\mu \times \mathrm{v})\left(\mathrm{y}_{1}, \mathrm{y}_{2}\right)\right\}$ $=\min \left\{(\mu \times \mathrm{v})\left(\left(\mathrm{x}_{1}, \mathrm{x}_{2}\right) *\left(\mathrm{y}_{1}, \mathrm{y}_{2}\right)\right) *\left(\mathrm{z}_{1}, \mathrm{z}_{2}\right)\right),(\mu \times \mathrm{v})$

$\left.\left(\mathrm{y}_{1}, \mathrm{y}_{2}\right)\right\}$

Hence $\mu \times v$ is a fuzzy T-ideal of a TM-algebra in $\mathrm{X} \times \mathrm{X}$.

Theorem 23: Let $\mu$ and $v$ be fuzzy sets in a TM-algebra $\mathrm{X}$ such that $\mu \times \mathrm{v}$ is a fuzzy T-ideal of $\mathrm{X} \times \mathrm{X}$. Then:

- (i) Either $\mu(0) \geq \mu$ (x) or $v(0) \geq v$ (x) for all $\mathrm{x} \in \mathrm{X}$

- (ii) If $\mu(0) \geq \mu$ (x) for all $\mathrm{x} \in \mathrm{X}$, then either $\mathrm{v}(0) \geq$ $\mu$ (x) or $v(0) \geq v(x)$

- (iii) If $\mathrm{v}(0) \geq \mathrm{v}$ (x) for all $\mathrm{x} \in \mathrm{X}$, then either $\mu(0) \geq$ $\mu$ (x) or $\mu(0) \geq v$ (x)

- (iv) Either $\mu$ or $v$ is a fuzzy T-ideal of $X$.

Proof: $\mu \times v$ is a fuzzy T-ideal of $X \times X$.

Therefore $(\mu \times \mathrm{v})(0,0) \geq(\mu \times \mathrm{v})(\mathrm{x}, \mathrm{y})$ for all $(\mathrm{x}, \mathrm{y}) \in \mathrm{X} \times \mathrm{X}$ and $(\mu \times \mathrm{v})\left(\left(\mathrm{x}_{1}, \mathrm{x}_{2}\right) *\left(\mathrm{z}_{1}, \mathrm{z}_{2}\right)\right) \geq \min \{(\mu$ $\left.\left.\left.x_{\mathrm{v}}\right)\left(\left(\mathrm{x}_{1}, \mathrm{x}_{2}\right) *\left(\mathrm{y}_{1}, \mathrm{y}_{2}\right)\right) *\left(\mathrm{z}_{1}, \mathrm{z}_{2}\right)\right),(\mu \times \mathrm{v})\left(\mathrm{y}_{1}, \mathrm{y}_{2}\right)\right\}$ for all $\left(\mathrm{x}_{1}, \mathrm{x}_{2}\right),\left(\mathrm{y}_{1}, \mathrm{y}_{2}\right)$ and $\left(\mathrm{z}_{1}, \mathrm{z}_{2}\right) \in \mathrm{X} \times \mathrm{X}$.

Suppose that $\mu(0)<\mu(\mathrm{x})$ and $\mathrm{v}(0)<\mathrm{v}$ (y) for some $\mathrm{x}, \mathrm{y} \in \mathrm{X}$.

Then:

$(\mu \times \mathrm{v})(\mathrm{x}, \mathrm{y})=\min \{\mu(\mathrm{x}), \mathrm{v}(\mathrm{y})\}$

$>\min \{\mu(0), \mathrm{v}(0)\}=(\mu \times \mathrm{v})(0,0)$,

a contradiction.

Therefore either $\mu(0) \geq \mu(\mathrm{x})$ or $\mathrm{v}(0) \geq \mathrm{v}(\mathrm{x})$ for all $\mathrm{x} \in \mathrm{X}$.

Assume that there exist $\mathrm{x}, \mathrm{y} \in \mathrm{X}$ such that: $\mathrm{v}(0)<\mu(\mathrm{x})$ and $\mathrm{v}(0)<\mathrm{v}(\mathrm{y})$.

Then:

$(\mu \times \mathrm{v})(0,0)=\min \{\mu(0), \mathrm{v}(0)\}=\mathrm{v}(0)$ and hence

$(\mu \times \mathrm{v})(\mathrm{x}, \mathrm{y})=\min \{\mu(\mathrm{x}), \mathrm{v}(\mathrm{y})\}>\mathrm{v}(0)=(\mu \times \mathrm{v})(0,0), \mathrm{a}$ contradiction.

Hence if $\mu(0) \geq \mu(x)$ for all $x \in X$, then either: $\mathrm{v}(0) \geq \mu(\mathrm{x})$ or $\mathrm{v}(0) \geq \mathrm{v}(\mathrm{x})$

Similarly we can prove that if $\mathrm{v}(0) \geq \mathrm{v}$ (x) for all $\mathrm{x} \in \mathrm{X}$, then either $\mu(0) \geq \mu(\mathrm{x})$ or $\mu(0) \geq \mathrm{v}(\mathrm{x})$.

First we prove that $\mathrm{v}$ is a fuzzy T-ideal of $\mathrm{X}$.

Since, by (i), either $\mu(0) \geq \mu(x)$ or $v(0) \geq v(x)$ for all $\mathrm{x} \in \mathrm{X}$.

Assume that $\mathrm{v}(0) \geq \mathrm{v}(\mathrm{x})$ for all $\mathrm{x} \in \mathrm{X}$.

It follows from (iii) that either $\mu(0) \geq \mu$ (x) or $\mu(0) \geq \mathrm{v}(\mathrm{x})$.

If $\mu(0) \geq v(x)$ for any $x \in X$, then: 
J. Math. \& Stat., 7 (2): 107-111, 2011

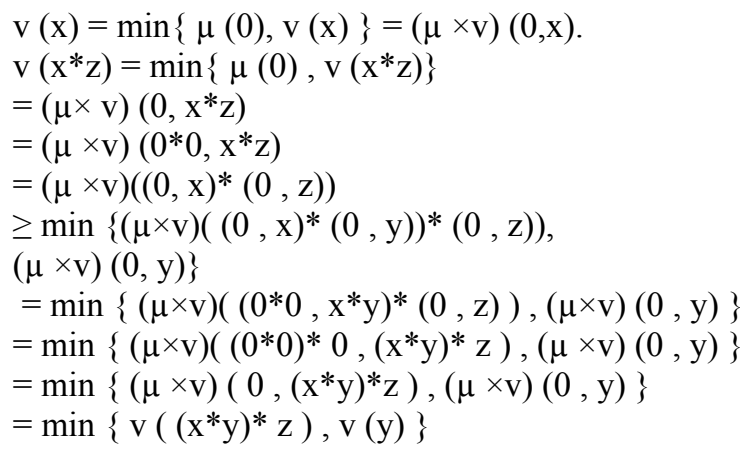

Hence $v$ is a fuzzy T-ideal of $X$.

Now we will prove that $\mu$ is a fuzzy T-ideal of $\mathrm{X}$.

Let $\mu(0) \geq \mu(\mathrm{x})$.

By (ii) either $\mathrm{v}(0) \geq \mu(\mathrm{x})$ or $\mathrm{v}(0) \geq \mathrm{v}(\mathrm{x})$.

Assume that $v(0) \geq \mu(\mathrm{x})$, Then:

$\mu(\mathrm{x})=\min \{\mu(\mathrm{x}), \mathrm{v}(0)\}=(\mu \times \mathrm{v})(\mathrm{x}, 0)$.

$\mu\left(\mathrm{x}^{*} \mathrm{z}\right)=\min \left\{\mu\left(\mathrm{x}^{*} \mathrm{z}\right), \mathrm{v}(0)\right\}$

$=(\mu \times v)\left(x^{*} \mathrm{z}, 0\right)$

$=(\mu \times \mathrm{v})\left(\mathrm{x}^{*} \mathrm{z}, 0 * 0\right)$

$=(\mu \times \mathrm{v})\left((\mathrm{x}, 0)^{*}(\mathrm{z}, 0)\right)$

$\geq \min \left\{(\mu \times \mathrm{v})\left(\left((\mathrm{x}, 0)^{*}(\mathrm{y}, 0)\right)^{*}(\mathrm{z}, 0)\right),(\mu \times \mathrm{v})(\mathrm{y}, 0)\right\}$

$=\min \left\{(\mu \times \mathrm{v})\left(\left(\mathrm{x}^{*} \mathrm{y}, 0 * 0\right) *(\mathrm{z}, 0)\right),(\mu \times \mathrm{v})(\mathrm{y}, 0)\right\}$

$=\min \left\{(\mu \times v)\left(\left(x^{*} y\right)^{*} \mathrm{z}, 0\right),(\mu \times v)(y, 0)\right\}$

$=\min \left\{\mu\left(\left(x^{*} y\right)^{*} \mathrm{z}\right), \mu(\mathrm{y})\right\}$

Hence $\mu$ is a fuzzy T-ideal of $X$.

Homomorphism of TM-algebras:

Definition 24: Let $\mathrm{X}$ and $\mathrm{Y}$ be TM-algebras. A mapping $\mathrm{f}: \mathrm{X} \rightarrow \mathrm{Y}$ is said to be a homomorphism if it satisfies:

$f\left(x^{*} y\right)=f(x)^{*} f(y)$, for all $x, y \in X$.

Definition 25: Let $f: X \rightarrow X$ be an endomorphism and $\mu$ a fuzzy set in $X$. We define a new fuzzy set in $X$ by $\mu_{\mathrm{f}}$ in $\mathrm{X}$ by $\mu_{\mathrm{f}}(\mathrm{x})=\mu(\mathrm{f}(\mathrm{x}))$ for all $\mathrm{x}$ in $\mathrm{X}$.

Theorem 26: Let $f$ be an endomorphism of a TMalgebra $X$. If $\mu$ is a fuzzy T-ideal of $X$, then so is $\mu_{\mathrm{f}}$.

Proof: $\mu_{\mathrm{f}}(\mathrm{x})=\mu(\mathrm{f}(\mathrm{x})) \leq \mu(0)$

$$
=\mu(\mathrm{f}(0))=\mu_{\mathrm{f}}(0) \text { for all } \mathrm{x} \in \mathrm{X}
$$

Let $\mathrm{x}, \mathrm{y}, \mathrm{z} \in \mathrm{X}$.

Then:

$$
\begin{aligned}
& \mu_{\mathrm{f}}\left(\mathrm{x}^{*} \mathrm{z}\right)=\mu\left(\mathrm{f}\left(\mathrm{x}^{*} \mathrm{z}\right)\right)=\mu(\mathrm{f}(\mathrm{x}) * \mathrm{f}(\mathrm{z})) \\
& \geq \min \left\{\mu\left(\left(\mathrm{f}(\mathrm{x})^{*} \mathrm{f}(\mathrm{y})\right)^{*} \mathrm{f}(\mathrm{z})\right), \mu(\mathrm{f}(\mathrm{y}))\right\} \\
& =\min \left\{\mu\left(\left(\mathrm{f}\left(\mathrm{x}^{*} \mathrm{y}\right)\right)^{*} \mathrm{f}(\mathrm{z})\right), \mu(\mathrm{f}(\mathrm{y}))\right\} \\
& =\min \left\{\mu\left(\mathrm{f}\left(\left(\mathrm{x}^{*} \mathrm{y}\right)^{*} \mathrm{z}\right)\right), \mu(\mathrm{f}(\mathrm{y}))\right\} \\
& \left.\left.=\min \left\{\mu_{\mathrm{f}}\left(\left(\mathrm{x}^{*} \mathrm{y}\right)^{*} \mathrm{z}\right)\right), \mu_{\mathrm{f}}(\mathrm{y})\right)\right\} .
\end{aligned}
$$

Hence $\mu_{\mathrm{f}}$ is a fuzzy T-ideal of $\mathrm{X}$.

\section{DISCUSSION}

With minimum conditions in TM-algebra it satisfy these results. In other algebras like $\mathrm{BCK} / \mathrm{BCI} / \mathrm{BCH} /$ $\mathrm{BCC}$ the number of conditions are more.

\section{CONCLUSION}

In this article, we have fuzzified the subalgebra and ideal of TM-algebras into fuzzy subalgebra and fuzzy ideal of TM-algebras. It has been observed that the TM-algebra satisfy the various conditions stated in the $\mathrm{BCC} / \mathrm{BCK}$ algebras and can be considered as the generalization of all these algebras. These concepts can further be generalized.

\section{REFERENCES}

Dudek, W.A. and Y.B. Jun, 2001. Fuzzification of ideals in BCC-algebras. Glasnik Matematicki, 36: 127-138.

Imai, Y. and K. Isaeki, 1966. On axiom systems of propositional calculi, XIV. Proc. Jap. Acad., 42: 19-22. DOI: $10.3792 / \mathrm{pja} / 1195522169$

Jun, Y.B., 2009. Generalization of $(\in, \in v q)$-fuzzy subalgebras in BCk /BCI-algebras. Comput. Math. Appl., $\quad$ 58: $1383-1390$. DOI: 10.1016/j.camwa.2009.07.043

Megalai, K and A.Tamilarasi, 2010. TM-algebra - An Introduction. Int. J. Comput. Applied., Special Issue Computer Aided soft Computing Techniques for imaging and Biomedical Application. DOI: 10.5120/996-29

Zadeh, L.A., 1965. Fuzzy sets. Inform. Control, 8: 338-353. DOI: 10.1016/S0019-9958(65)90241-X 